\title{
Hydrophone VSP surveys in hard rock
}

\author{
Andrew Greenwood ${ }^{1}$, Christian J. Dupuis ${ }^{1}$, Milovan Urosevic ${ }^{1}$, and Anton Kepic ${ }^{1}$
}

\begin{abstract}
Seismic imaging in hard rock environments is gaining wider acceptance as an exploration technique and as a mine-planning tool. To date, 13 successful case studies have been acquired in Australia. The images generated from hard rock targets exhibit large levels of complexity and their interpretations remain an active area of study. To assist the imaging and better understand the source of the reflections observed, vertical seismic profiling (VSP) can be employed. This technique is not readily applied to hard rock environments because cost and operational issues often prove prohibitive. We propose the use of hydrophone arrays as a cost effective solution to VSP acquisition. We highlight the key challenges in using these receivers and propose solutions to overcome them. By careful acquisition methodologies and refined signal processing techniques, the tube waves that have up to now compromised the use of hydrophones for VSP acquisition can be effectively mitigated. We show that the data acquired with hydrophones compare favorably to that acquired with conventional $3 \mathrm{C}$ geophones. The data acquired with hydrophones come at a fraction of the cost and deployment time required for conventional acquisition procedures. Our results show that hydrophone vertical seismic acquisition is a viable, cost effective, and efficient solution that should be employed more routinely in hard rock environments to enhance the value of the surface data sets being acquired.
\end{abstract}

\section{INTRODUCTION}

The seismic method is considered an ideal remote sensing tool for deep exploration because it maintains resolution with depth. However, in hard rock environments, the limited variations in elastic parameters, thick, highly heterogeneous regolith, fractal geology, reactivated, altered, and highly fractured zones cause significant scattering of seismic energy (Urosevic et al., 2005). These factors combine to produce complex seismic responses and highly variable reflection patterns. To alleviate these problems, at least partially, vertical seismic profiling (VSP) places the receiver downhole. Downhole receivers eliminate many of the noise sources associated with the surface seismic method such as wind, air waves, surface waves, electrical radio frequency (RF), and irregular near surface layers (Hardage, 2000). Also, the wavefield is distorted only on the way down by the low-velocity regolith layer; it then heals before it is received by the borehole receiver. Consequently, the signal-tonoise ratios $(\mathrm{S} / \mathrm{N})$ and resolution of seismic images recorded below the surface can be much higher than seismic signals recorded on the surface. However, the limited lateral aperture of downhole receivers restricts the spatial extent of imaging from boreholes. Nevertheless, due to the specific geometry of VSP, transmitted and reflected wavefields can be recorded. Thus, it is possible to understand the origin of reflection events (Gulati, 1998) with direct correlation to drill-core logs and wire-line data. This is of great importance for the interpretation of complex seismic images. Therefore, it is essential to incorporate the use of borehole seismology and geologic information into the image processing and interpretation of seismic data (Urosevic et al., 2007).

Surface seismic methods are becoming recognized as a viable tool in deep mineral exploration, yet only a few hard rock exploration VSP surveys have been publicly documented in the literature (Juhlin, 1990; Miao et al., 1995; Eaton et al., 1996; Adam et al., 2000; Cosma, 2003; Perron et al., 2003). The Bell Allard Orebody in Mattagami, Quebec is most likely the most published case. At the Bell Allard Orebody site, a 2D surface seismic line located a 1-kmdeep anomaly believed to originate from massive sulfides (Calvert and $\mathrm{Li}, 1999)$. Due to the possibility of out-of-plane reflections from complex dipping structures, VSP was employed to confirm the existence of the orebody. Two boreholes were drilled and VSPs conducted. One borehole intersected the massive sulfide deposit and the VSP conducted in the other borehole imaged a basalt/rhyolite contact $200 \mathrm{~m}$ to the northeast of the deposit (Adam et al., 2000). In Sweden, imaging of internal fractures in Precambrian

\footnotetext{
Manuscript received by the Editor 1 December 2011; revised manuscript received 8 May 2012; published online 6 September 2012.

${ }^{1}$ Curtin University, Deep Exploration Technologies Commonwealth Research Consortium, Department of Exploration Geophysics, Perth, Australia. E-mail: andrew.greenwood@postgrad.curtin.edu.au; c.dupuis@curtin.edu.au; m.urosevic@curtin.edu.au; a.kepic@curtin.edu.au.

(C) 2012 Society of Exploration Geophysicists. All rights reserved.
} 
crystalline rocks was presented by Juhlin et al. (1991). Juhlin et al. (1991) used surface seismic and VSP to verify the ability of the seismic method to map internal composition and fractures. The results were confirmed with correlation to wire-line logs and borehole drill-core analysis. Similarly, multiazimuth VSP has been used to identify and characterize crystalline rocks and fracture zones at a deep nuclear waste disposal site in Finland (Cosma and Heikkinen, 1996). In New Brunswick, Canada, VSP was trialed at the HalfMile Lake massive sulfide deposit to test the viability of VSP for imaging a known orebody. Multioffset and multiazimuth VSP successfully located a deep sulfide lens connected to the orebody but was unable to image its shape accurately (Bellefleur et al., 2004).

\section{VSP SURVEYS WITH HYDROPHONES}

Mineral exploration boreholes are typically diamond drilled with small diameter HQ, NQ, or BQ sized coring bits (96, 76, and $60 \mathrm{~mm}$ borehole diameters, respectively). The boreholes are commonly stepped down in diameter with depth, frequently finishing with a BQ tail at the target depth. The boreholes are usually deviated such that they intersect high-dipping lithology orthogonally. The highly altered and fractured nature of the rock means that the boreholes drilled this way are often unstable. As such, drill rods are often left in the upper sections of the borehole to facilitate geophysical or wire-line surveys, further reducing the effective borehole diameter. This is to stabilize unstable sections while allowing open-hole access to the lower sections. With such formations and no cemented casing, the logistical risk of operating clamping geophones in this environment has slowed adoption of VSP in mineral exploration. Few "slim-line" borehole geophone tools are available (e.g., the $55 \mathrm{~mm}$ RD-XYZH and $48 \mathrm{~mm}$ AMC-VSP-3-48M). These tools require approximately $10 \mathrm{~mm}$ clearance for clamping arm operation; they are costly, and each geophone shuttle weighs between 6 and $15 \mathrm{~kg}$. Deployment of multiple shuttles becomes logistically difficult due to potential formation damage in altered zones. Often, the risk can outweigh the cost of a mineral exploration borehole. Thus, shuttles are typically restricted to strings of eight or less, but more commonly only one or two. The limitation of a small shuttle count is that it requires multiple moves in the borehole to acquire full borehole coverage, which is time expensive and requires repeat shooting at the surface, thus increasing acquisition costs. The limitation also makes it difficult to separate different wavefields, and the source wavelet repeatability of multiple shots becomes a significant factor in data quality.

Hydrophones seem a logical alternative to the conventional borehole geophone tool. They can be engineered to be very sensitive, broadband, slim-line (O. D. $<40 \mathrm{~mm}$ ), lightweight, and rapidly deployable. The ease of deployment comes from the ability of the hydrophone to couple to the formation via the fluid in the borehole. Because the sensors are not clamped, potential borehole damage is avoided. Finally, hydrophone strings of 24 to 48 or more receivers can be manufactured for a similar cost as a single slim-line $3 \mathrm{C}$ shuttle. These strings can cover tens to hundreds of meters of borehole aperture per shot and thus significantly reduce acquisition time.

Hydrophones have been tested for the purpose of borehole surveying by several authors (Huang and Hunter, 1984; Marzetta et al., 1988; Milligan et al., 1997; Greenhalgh and Bierbaum, 2000; Gulati et al., 2001). The applications, however, have been limited to velocity determination and borehole tomography applications due to contamination of the records by strong coherent tube waves. Marzetta (1988) compared a clamped vertical geophone and three-element hydrophone array in the Schlumberger test well in France. He observed a strong reflected event with the hydrophone array that was also observed by the clamped geophone. However, the recovery of weaker reflected signals that were masked by tube waves was not possible with the limited acquisition geometry of the system used. In a 2D surface experiment, Gulati (2001) compared a buried geophone with a borehole hydrophone at $18 \mathrm{~m}$ depth. The experiment used a dynamite source with offsets at $20 \mathrm{~m}$ spacing $\pm 1500 \mathrm{~m}$ from the borehole. He noted in his experiment that it is likely possible to create a seismic image from the reflections observed in his data.

These early borehole hydrophone data acquisition reports were encouraging, and the low cost along with all the other advantages previously discussed motivated this research program. The efforts of this research program have been devoted to demonstrating the successful use of a 24-channel hydrophone string as an alternative VSP system for use in hard rock environments. Concentration has been on developing procedures that effectively sample and attenuate tube-wave noise. Field experiments have included the testing of different drilling fluids and a novel tube-wave baffling system (Greenwood et al., 2012). Careful acquisition methodologies combined with refinements in signal processing have been used to remove tube waves in hard rock hydrophone VSP data and high-quality seismic images obtained. Hydrophone VSP wavefield-separated profiles have been evaluated against a clamping geophone VSP. The hydrophone experiments were conducted in a mineral exploration borehole drilled into the largest hard rock 3D surface seismic survey conducted in Australia to date.

\section{TUBE-WAVE SAMPLING AND REMOVAL}

Tube waves are interfacial waves that travel along the borehole/ fluid interface. They appear on shot records as coherent linear events because tube waves and receivers coexist along the axis of the borehole. Tube waves can be excited at all seismic frequencies and overlap the seismic signals of interest (40 to $250 \mathrm{~Hz}$ ). They propagate by displacing particles within the borehole fluid and particles (in compliant rocks) in a small annulus around the borehole (Hardage, 2000). Particle motion in the borehole fluid is prograde elliptical away from the borehole wall and pure rectilinear in the center of the borehole. The radial axis of displacement is continuous at the borehole boundary, whereas the axial component is discontinuous at the interface (White, 1983). The axial component of motion is much larger than the radial component. The axial component in hard formations is larger within the fluid column by a factor of 20 at $400 \mathrm{~Hz}$ and a factor of 100 at $75 \mathrm{~Hz}$ (Cheng and Töksoz, 1982).

Tube-wave amplitudes in hydrophone data are often at least an order of magnitude greater than direct seismic signals, and two or more orders of magnitude larger than any seismic reflection events. Tube waves are generated from the Rayleigh surface wave crossing the top of the fluid column, or from body waves interacting with discontinuities in the borehole and borehole wall. Body-waveinduced tube waves are caused at sudden changes in borehole diameter (washouts, drill rod changes), borehole condition (fractures, shears), large impedances contrasts in the borehole (such as casing), difference in elastic (shear) properties between various rock units, and from body-waves incident on water-filled fractures, creating a squirt at the borehole. These induced tube waves are the most 
damaging in hard rock hydrophone VSP profiles; due to the highly fractured nature of the rock, their occurrence is unpredictable and their characteristic chevron shape masks the later times in the shot record where body-wave reflections are expected. To determine the source of a tube wave, we trace its propagation in the record back to the surface or its intersection with the direct P-wave arrivals, thus determining its depth of origin and then correlating with borehole construction and geology logs. In Figure 1, different types of tube waves experienced in a hydrophone VSP survey are shown. Here, it can be noted that the direct arriving P-wave is weak $(90 \mathrm{mV})$ compared to the high-amplitude tube waves $(4000 \mathrm{mV})$ and there is no evidence of S-wave or reflected wavefields because most of the profile is masked by the induced tube waves.

Methods for reducing the amplitude of the Rayleigh and casing tube-wave effects are to increase the shotpoint distance from the collar, trenching between the shot and borehole, or reduce the water table (White, 1983; Gulati et al., 2001). None of these methods are particularly effective when the shot is in direct contact with consolidated rock, and none of the methods solve the issues of induced tube waves. Milligan (1997) tried baffling the Rayleigh and casing tube waves with closed-cell foam attached to the hydrophone array above the top element. This was successful in suppressing the tube waves at shallow depths $(<50 \mathrm{~m})$; however, at greater depths, the foam collapsed under confining pressure and thus reduced suppression of the tube wave. Recent trials by Greenwood et al. (2012) have suppressed tube-wave propagation with a unique baffle system. These baffles create self-destructive interference in the axial

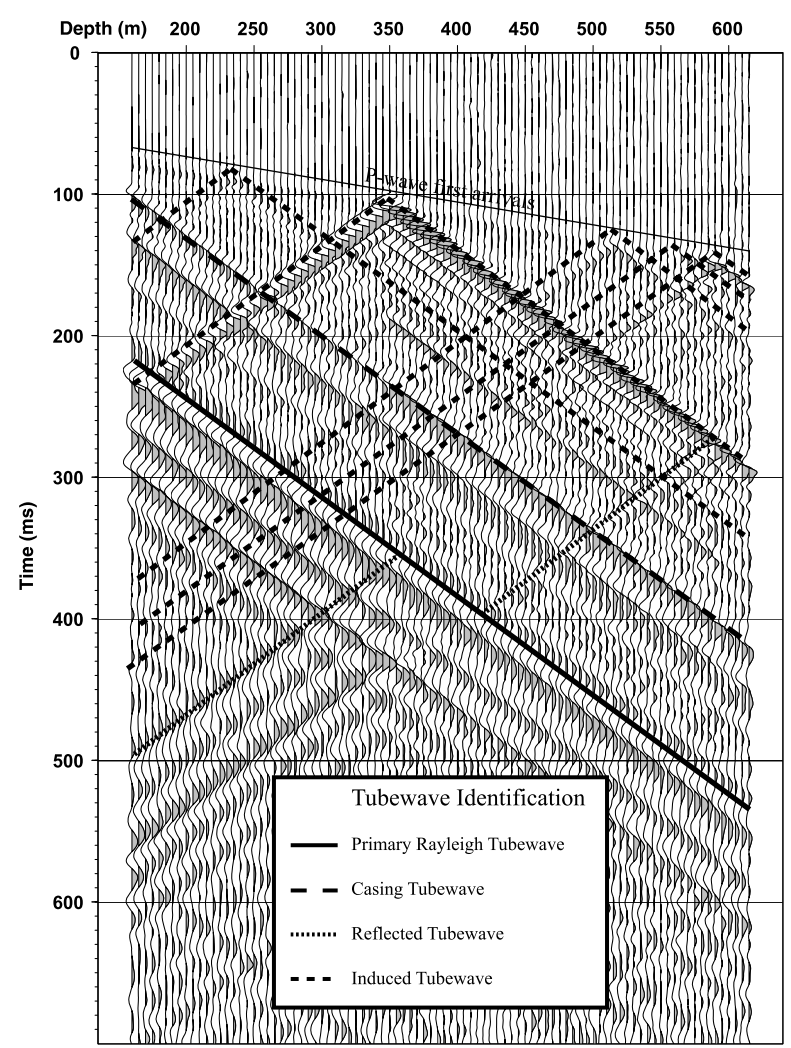

Figure 1. Identification of tube waves typically found in a hard rock hydrophone VSP survey. Induced tube waves from large changes within the borehole occupy most of the record, masking potential reflections at later times. direction of the borehole and are not subject to depth limitations (Greenwood et al., 2012). This baffle system had not been developed prior to the research presented here. Another significant result of trials by Greenwood et al. (2011) is the use of high-viscosity drilling fluid. Very high-quality borehole hydrophone data were collected with a hydrophone array suspended in high-viscosity drilling fluid. The viscoelastic fluid increased coupling of the hydrophone to the formation, increased the $\mathrm{S} / \mathrm{N}$, and reduced axial displacement of the tube wave, further increasing the $\mathrm{S} / \mathrm{N}$. The drilling fluid experiment was conducted in $\mathrm{BH} 2$ of the Kambalda test site. The data from this experiment are displayed in Figure 2. Figure 2 shows reduction of the $\mathrm{P}$-wave and tube-wave amplitude disparity, the presence of a strong S-wave, and the P- and S- wavefields are well defined in the $f$ - $k$ spectrum.

The single most important process in VSP imaging is separation of the transmitted and reflected wavefields. This includes the removal of unwanted waves such as tube waves. Successful wavefield separation processing requires the data to be collected with the correct spatial sampling to avoid aliasing in the frequency band of interest. Correct spatial sampling is determined from

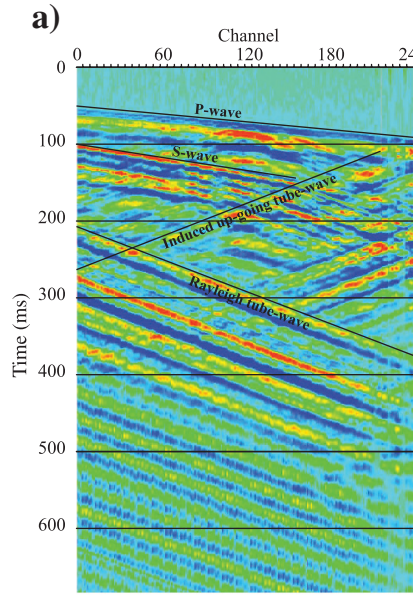

c)

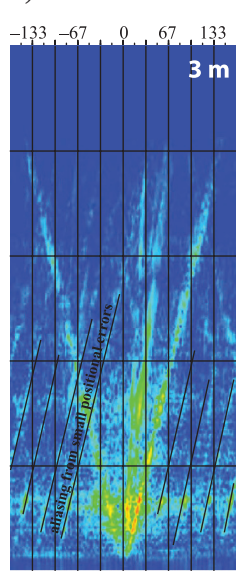

b)

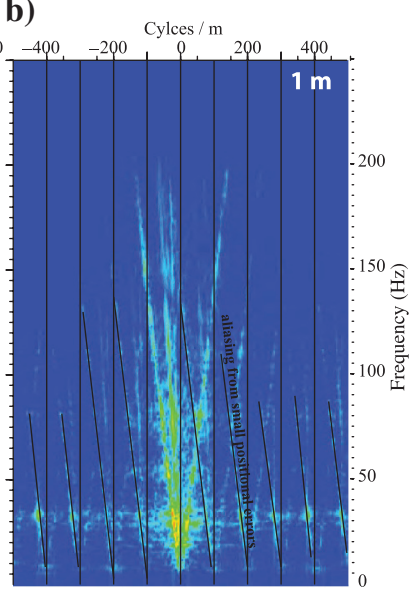

d) e)

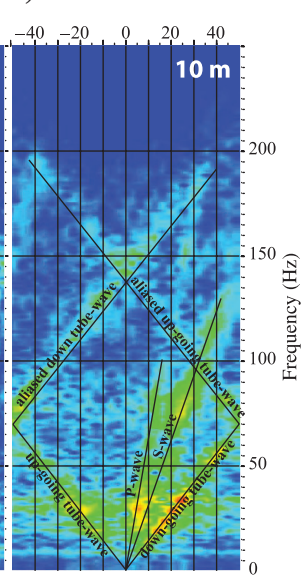

Figure 2. Analysis of tube-wave aliasing in the $f-k$ domain. Data were collected with a 24-channel hydrophone string with elements spaced at $10 \mathrm{~m}$. The string was repositioned in $1 \mathrm{~m}$ increments to obtain a 240-channel gather shown as panel (a). The lower panels are the $f-k$ spectrums after downsampling the data to $3 \mathrm{~m}$ (c), $5 \mathrm{~m}$ (d) and $10 \mathrm{~m}$ (e) receiver station spacings. 
the slowest wave velocity and highest frequency of interest (Station Interval $=V_{\min } / 2 f_{\max }$ ). If hard rock VSP survey design is based solely on the expected P- and S-wave velocities (typically above 5000 and $3000 \mathrm{~m} / \mathrm{s}$, respectively), then the tube waves will be aliased. Tube waves are the slowest waves in hard formations with an approximate velocity of $1480 \mathrm{~m} / \mathrm{s}$ and results in aliasing at approximately 75 and $150 \mathrm{~Hz}$ for 10 and $5 \mathrm{~m}$ spaced receivers. Tube-wave aliasing is demonstrated in Figure 2 with data that has been collected at $1 \mathrm{~m}$ station separations and disseminated down to 3,5 , and $10 \mathrm{~m}$ station profiles. Of special note here is that the 5,3 , and $1 \mathrm{~m}$ data have events that are aliased in the wavenumber domain. This is due to small errors in station positioning. The data were collected with a 24-channel hydrophone string and incrementally moved at $1 \mathrm{~m}$ stations to simulate a $1 \mathrm{~m}$ station separation profile.

Clamping geophones have long been the preferred downhole seismic sensor for borehole reflection seismic applications. This is due to their ability to directly measure particle motion at the borehole wall and being clamped to the borehole wall means they are invulnerable (but not immune) to particle movement within the borehole fluid. To substantiate borehole hydrophone arrays as an alternative VSP imaging tool, it was necessary to bench test the method's ability to record, discriminate, and separate out different wavefields and compare the results with clamping geophones. To achieve this, a hydrophone VSP and a clamping geophone VSP

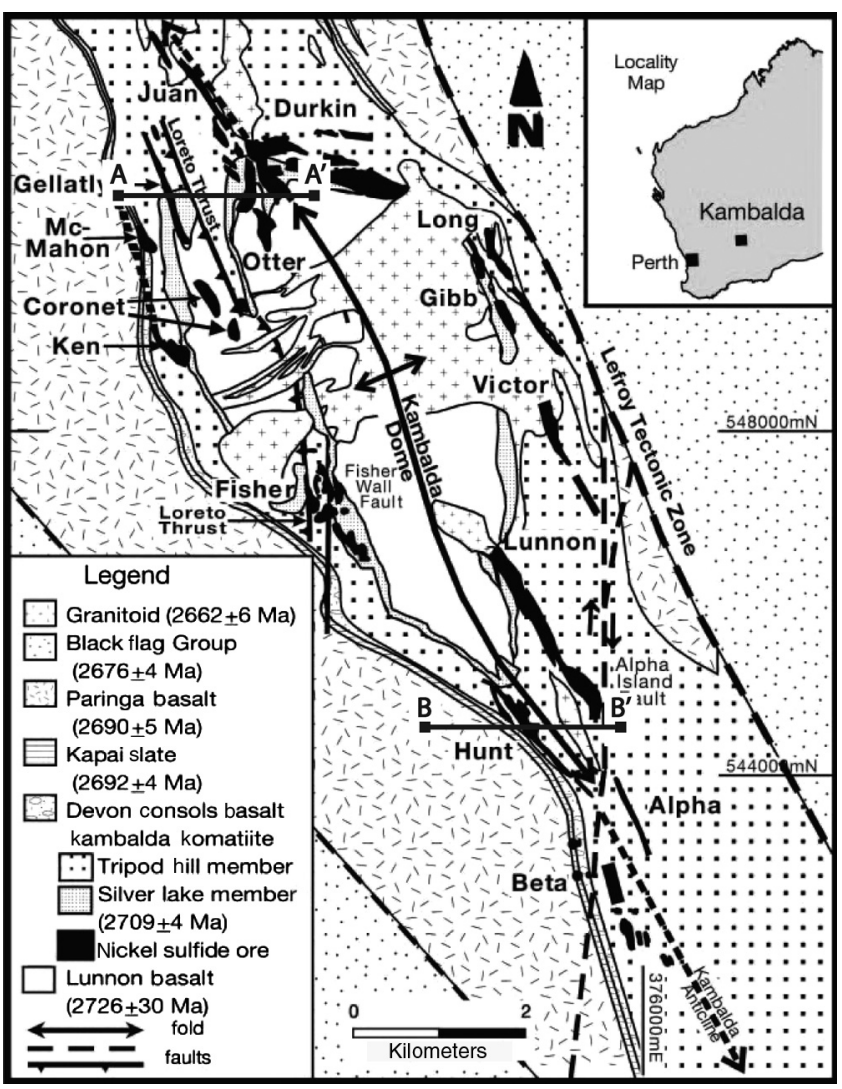

Figure 3. Regional structure and surficial geology of Kambalda. Regional tectonics control the architecture and formation of the Kambalda Dome, a north-northwest-south-southeast double plunging anticline. Locations of cross-sections A-A' and B-B' of Figure 6 and 4 are shown. From (Stone et al., 2005). were conducted within a hard rock exploration borehole in Kambalda, Western Australia.

\section{KAMBALDA EXPERIMENT}

Kambalda is a world class nickel and gold mining district with a premined reserve of approximately 35 million metric tons containing 3\% nickel (Gresham, 1986; Stone and Masterman, 1998). It is located in the south-central part of the Norseman-Wiluna Greenstone belt of the Yilgarn Craton, Western Australia (Figure 3), and is considered a type section for Archean komatiite-associated nickel sulfide deposits. Regional scale tectonics control the architecture of Kambalda, which is dominated by the north-south faulting and folding (Beresford et al., 2002) that has formed the Kambalda Anticline. A fold structure within this forms the Kambalda dome and is shown in Figure 3. The Kambalda Dome plunges to the north; it is centered with a felsic intrusion (granite) and is truncated to the east by the Lefroy fault (Greenhalgh et al., 2000; Stone et al., 2005). Volcaniclastics and komatiites overlie the flanks of the dome and have undergone multiple suites of mafic (dolerite) and felsic (granite) intrusions, as well as metamorphism between the upper greenschist to lower amphibole facies (Stone and

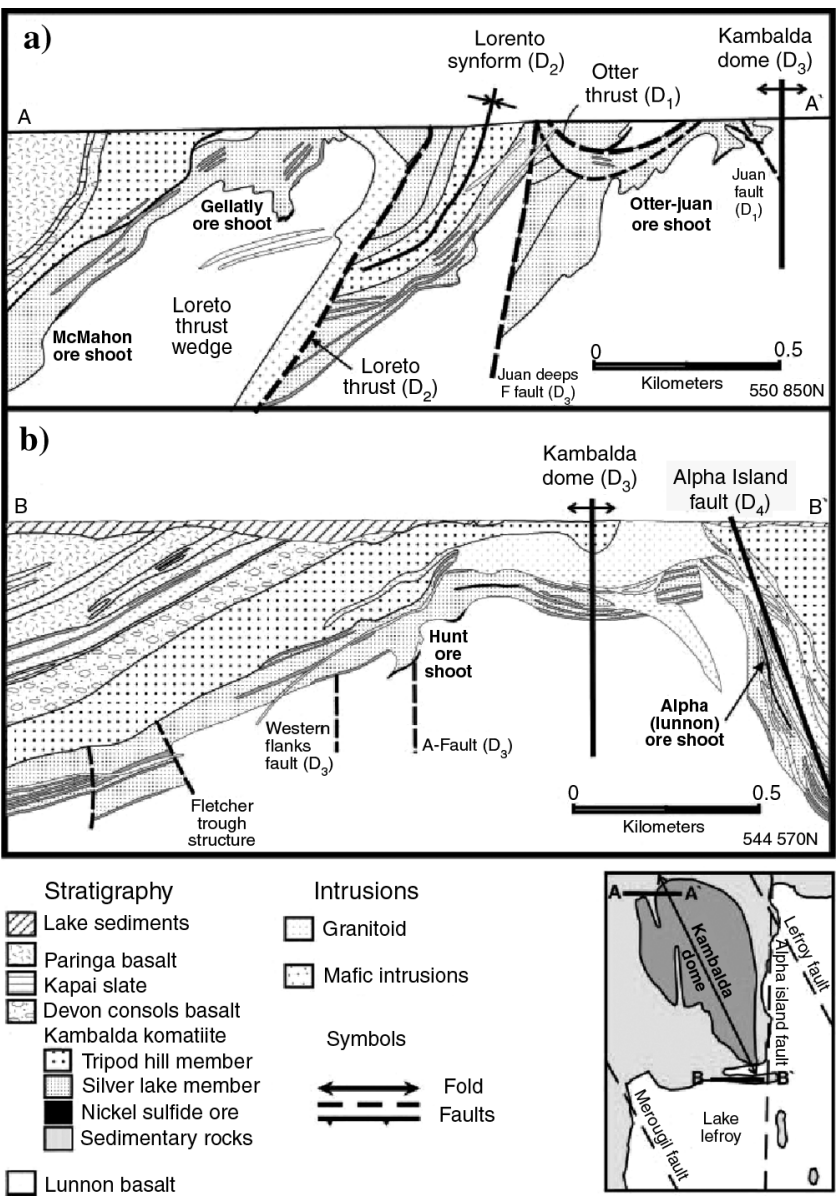

Figure 4. (a) Cross section across the northwest flank of the Kambalda Dome. West-dipping reverse faults have formed a series of wedges of the Lunnon Basalt footwall. (b) Cross section of the south part of the Kambalda Dome. The thickness of the ore shoots, sedimentary units, and felsic intrusions have been exaggerated for clarity. (From Stone et al., 2005). 
Archibald, 2004). Exploration targets nickel sulfides that accumulate at the base of the Kambalda Komatiites (Tripod Hill and Silver Lake members) in contact with the top of the Lunnon Basalt. Two geologic cross sections, transecting the north and the south of the Kambalda Dome are shown in Figure 4. Cross-section B-B' in the south illustrates the structure and lithology of the Kambalda Dome. Cross-section A-A' in the north is more complex and shows significant reverse faulting and stacking of sequences.

In 2009, a large mine-scale exploration 3D seismic survey that covered $27.4 \mathrm{~km}^{2}$ was conducted to the north of Kambalda. This survey is the largest Australian hard rock 3D surface seismic survey to date. Shown in Figure 5 is the location of the survey area and the extent of the $3 \mathrm{D}$ surface seismic receivers, the surficial regional geology, the collars of boreholes $\mathrm{BH} 1$ and $\mathrm{BH} 2$, and the location of cross-section A-A' some $4 \mathrm{~km}$ south of $\mathrm{BH} 1$. The survey area is surrounded by active mining tenants; however, the site is considered in the greenfields exploration phase with only boreholes $\mathrm{BH} 1$ and $\mathrm{BH} 2$ having been drilled at the time of this research. Boreholes $\mathrm{BH} 1$ and $\mathrm{BH} 2$ were diamond core drilled with PQ drill rods $(123 \mathrm{~mm}$ diameter and uncommon for deep holes in the area) to target depths of 1061 and $1204 \mathrm{~m}$, respectively. Hydrophone VSP surveys were conducted in both holes with the primary aim of depth calibrating the $3 \mathrm{D}$ surface seismic. Secondary to this was to determine the origin of reflectors observed within the 3D seismic data. Initial borehole targeting was based on early inspection of the seismic 3D time volume.

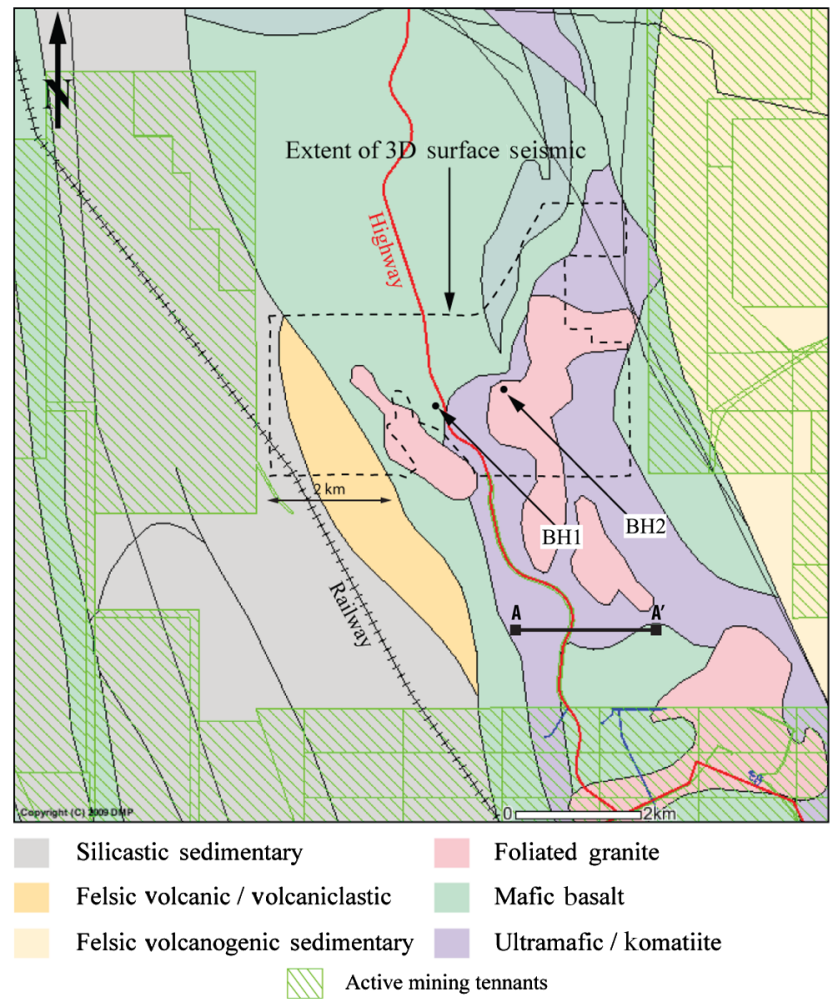

Figure 5. Surface geology of the Kambalda 3D surface seismic and VSP test sites. The locations of boreholes BH1, BH2, and crosssection A-A' (Figure 4) are shown. Active mining tenants (green hashed areas) surround the survey area (Government of Western Australia, Department of Mines and Petroleum).
BH2 did not intersect the Lunnon Basalt, but paralleled a shear and remained in granite for most of the hole $(770 \mathrm{~m})$. This was not considered representative of the regional geology profile and deemed unsuitable for time-to-depth calibration of the seismic $3 \mathrm{D}$ volume. BH1 also intersected $585 \mathrm{~m}$ of granite intrusion; however, it did terminate in a sequence of alternating basalts and granite. The geology summary log of BH1 is shown in Figure 6 as well as full-waveform sonic (FWS) data, natural gamma log, synthetic density, and a "blocky" density model. The blocky density model was created from specific gravity (SG) measurements taken on drill-core samples. Inverse Gardner's equation was used to calculate density from the FWS P-wave velocity data. Gardner's equation is an empirical relationship that states that density $(\rho)$ is proportional to the one-quarter power of the P-wave velocity $\left(V_{\mathrm{P}}\right)$ such that $\rho=\alpha V_{P}{ }^{\beta}$, where $\alpha$ is 0.31 when $V_{\mathrm{P}}$ is in $\mathrm{m} / \mathrm{s}$ and $\beta$ is equal to 0.25 (Sheriff, 2002). These values for the constants $\alpha$ and $\beta$ generally work well in petroleum exploration; however, in hard rock, they require calibration to the geology. No single set of constants was found that could accurately represent the geologic contrasts between granite, basalts, and the komatiites. Instead of implementing a set of empirically developed coefficients for these geologic units, a blocky density model was developed from SG core measurements. This model and the $V_{\mathrm{P}}$ (FWS) data were then used to calculate an acoustic impedance (AI) $\log$ and reflectivity function (Figure 6).

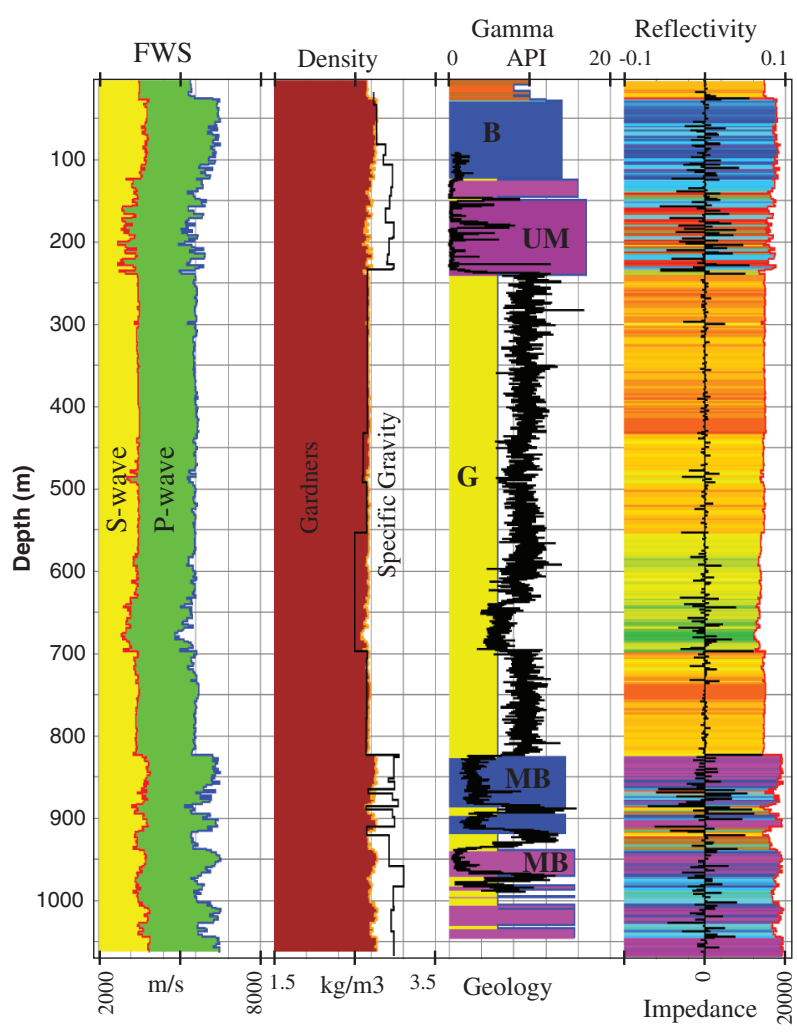

Figure 6. BH1 borehole logs. From left to right: Track 1: Fullwaveform sonic P-wave and S-wave data. Track 2: Density data derived from Inverse Gardner's relationship (solid brown) and measured from rock samples (black). Track 3: Natural gamma (black) and summarized geology where B-Basalt, G-Granit, MB-Mafic Basalt, and UM-Ultramafic. Track 4: Calculated acoustic impedance (colored amplitude plot) and reflectivity (black). 
Of significance in the stratigraphy is a large section within the granite unit between 555 to $695 \mathrm{~m}$ where FWS velocities and density vary. These variations have been identified as an alteration zone from inspection of the drill core. Some mineralization was also observed along fractures within the alteration zone. The variances in velocities and density were confirmed from core sample testing.

Ultrasonic pulse-transmission (PT) tests were conducted on 47 drill-core samples after the VSP survey. Sample depths were chosen based on anomalies seen in the VSP data and from visual inspection of the core. The PT tests were conducted using polarized shearwave transducers and a signal generator set at $1.0 \mathrm{MHz}$, the resulting acoustic waveforms for each sample were recorded digitally, the $\mathrm{P}$ - and S-wave arrival times were picked on screen, the length of the core samples were measured, and the $\mathrm{P}$-wave and $\mathrm{S}$-wave $\left(V_{\mathrm{S}}\right)$ velocities calculated. Specific gravity was also measured using $\mathrm{Ar}-$ chimedes' principle. Crossplots of $V_{\mathrm{P}}$ and $V_{\mathrm{S}}$ versus $\mathrm{SG}$ and $V_{\mathrm{P}} / V_{\mathrm{S}}$ are shown below in Figure 7. P-wave and SG determined from core samples have also been plotted overlying FWS P-wave data in Figure 7. Distinct groups of densities with small distributions of $V_{\mathrm{P}}$ and $V_{\mathrm{S}}$ can be observed in the data except in the density range 2.9 to $3.0 \mathrm{~g} / \mathrm{cm}^{3}$. P-wave velocities for the data set range between approximately 4500 to $6800 \mathrm{~m} / \mathrm{s}$; S-wave velocities range between approximately 2700 to $4200 \mathrm{~m} / \mathrm{s}$, and the average $V_{\mathrm{P}} / V_{\mathrm{S}}$ ratio is 1.70. A relationship between PT velocity, FWS, and SG measurements can be made in the granite and lower basalt units where the different data sets follow the same trend. However, the ultramafic units do not follow this trend and have an anomalously low velocity with respect to the mafic basalts of similar density.

\section{FIELD PARAMETERS}

Zero-offset hydrophone and 3C VSP data sets were acquired in BH1 (Figure 5) using equivalent source and acquisition geometry. Receivers were stationed between 95 to $1000 \mathrm{~m}$ depth at $5 \mathrm{~m}$ spacing; a near-offset shotpoint was positioned $28 \mathrm{~m}$ away with the drilling sumps separating (acting as trenches) the shotpoint and borehole collar. BH1 is deviated approximately $15^{\circ}$ with respect to the surface seismic crosslines (bearing $195^{\circ}$ ) and dips $82^{\circ}$ to the south. An $800 \mathrm{~kg}$ weight drop hammer hydraulically operated on a Caterpillar 287c skid-steer was used as the seismic source. The $3 \mathrm{C}$ data were collected with two $5 \mathrm{~m}$ spaced AMC-VSP-3-48M shuttles supplied and operated by ASTO Geophysical Pty Ltd. Multiple shots were required to span the $900 \mathrm{~m}$ receiver aperture at $10 \mathrm{~m}$ shuttle moves over the period of two half-day shifts. A reference geophone was placed near the borehole collar to correct for potential trigger (zero-time) variations. The hydrophone data were collected using a 24-channel string manufactured by VCable with elements spaced every $10 \mathrm{~m}$ and a 24-channel DAQ-Link III seismograph. The hydrophone string was repositioned eight times to span the $900 \mathrm{~m}$ receiver aperture at $5 \mathrm{~m}$ stations over the period of one-third of a day. A period of 15 to 20 minutes was required between string moves to allow the water column to settle and to allow the hydrophone elements to bleed off excess DC voltage induced by the change in hydrostatic pressure (230 $\mathrm{m}$ head changes). A reference geophone was not possible with the hydrophone configuration due to the seismograph channel limitation.

Multiple shots were taken for each receiver position and recorded individually. The individual records were edited for bad and excessively noisy traces, then stacked and gathered to form zero-offset VSP profiles. To account for tool precession in the borehole, rotation of the $3 \mathrm{C}$ data was required. This was performed using hodogram analysis, which maximizes $\mathrm{P}$-wave energy onto the vertical component $(\mathrm{P})$, and the vertically polarized $\left(S_{V}\right)$ and horizontally polarized $\left(S_{H}\right)$ shear-wave energies onto the Transverse 
(T) and Radial (R) horizontal directions with respect to source location. The raw hydrophone (W), P, R, and T profiles are shown in Figure $8 \mathrm{~d}$ and $8 \mathrm{a}$ to $8 \mathrm{c}$, respectively. Upon inspection of the $\mathrm{W}$ profile, it is immediately obvious that the data are contaminated by tube-wave energy, particularly at the top of the borehole until $230 \mathrm{~m}$. It is also interesting to note that this section is also noisy in the $\mathrm{P}, \mathrm{R}$, and $\mathrm{T}$ data. Downgoing $\mathrm{P}$-energy $\left(P_{d}\right)$ can be seen in the $\mathrm{W}, \mathrm{P}$, and $\mathrm{T}$ profiles, and $\mathrm{S}$-energy is evident in all profiles. The only upgoing energy (except tube waves) can be seen in the P, T, and R data. Converted P- to S-wave is visible at 230, 595, 700, and $850 \mathrm{~m}$ depth, as well as reflected S-wave at $700 \mathrm{~m}$. The depths at which these $\mathrm{P}$ - to $\mathrm{S}$-wave conversions occur roughly divide the profile into five sections where different slopes (velocities) and signal characteristics can be defined. The $\mathrm{P}$ - to $\mathrm{S}$-wave conversions and zones these define are marked in Figure $8 \mathrm{~b}$ and following figures.

\section{TUBE-WAVE ATTENUATION PROCESSING}

then used to flatten the data and determine sample amplitudes. The advantage of this method is that the operator is applied to one trace at a time, reducing the amount of trace-to-trace smearing typical of $2 \mathrm{D}$ median or $f$ - $k$ filters and it is adaptive (i.e., it is allowed to change spatially and temporally). Successful application of this technique for tube-wave removal in hydrophone data requires adaptation. The spatial window used in this study was restricted to six traces because the tube-wave energy is very coherent. This ensures that wavelet variations due to interference of other wavefields were not captured in the wavelet modeling. The temporal window length was set to $600 \mathrm{~ms}$ to capture the entire Rayleigh and Casing tube wavetrains. This window was guided along moveout, picked on the earliest high-amplitude tube-wave (casing tube wave), and given a $-550 \mathrm{~ms}$ starting offset. The offset is required to capture tube waves above the picked horizon. This routine was run on the individual hydrophone field records (FFID domain) after bad shot editing and a mild band-pass filter (5 to

Typically, VSP data are sorted to a commonshot gather for processing. This is necessary when dealing with $3 \mathrm{C}$ data collected with a single or small number of shuttles because wavefield separation processing techniques require multiple neighboring traces.

In the case of the hydrophone data, the data were collected with $24 \times 10 \mathrm{~m}$ spaced elements repositioned to collect at $5 \mathrm{~m}$ stations. If the $\mathrm{S} / \mathrm{N}$ is poor due to random noise, trigger errors, and variations in arrival times of the Rayleigh tube wave are present (caused by fluctuating water levels with string moves), then creation of a common-shot gather will create misalignments and amplitude imbalances in the shot gather. This in turn will cause artifacts during processing. Variations in late arriving Rayleigh tube waves have been highlighted in ellipse $i$ of Figure 8d. These water level-induced variations manifest as out-of-phase tube-wave events flip flopping between traces. Due to the way in which the hydrophone $5 \mathrm{~m}$ spaced (infill) data were collected, it is difficult to equalize trace-to-trace signal and noise events. As such, it has been found that it is beneficial to precondition the individual field records (FFID domain), balance trace amplitudes, and perform wavefield separation in the FFID domain prior to stacking and creating a common-shot gather.

A wavefield extrapolation technique based on the wave-by-wave optimization approach of Blias (2007) was trialed to remove tube-wave noise from the hydrophone data. This method examines the data within a defined time window over a defined number of traces, which is guided along a picked horizon. It then creates a model wavelet and adaptively subtracts it from the data trace by trace. The routine determines the waveshape function for each wavefield ( $r$ ), amplitude (a) and time $(\tau)$ functions from the initial conditions (picked horizons) and solves the Eigenvalue problem to determine time shifts, which is
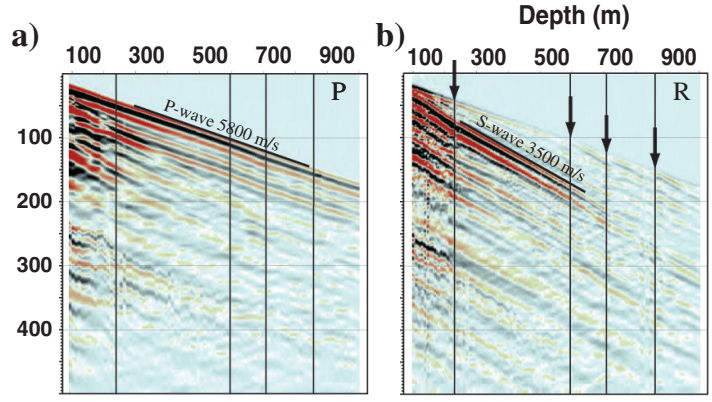

d)

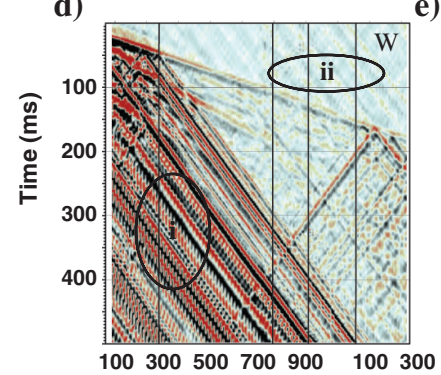

e)

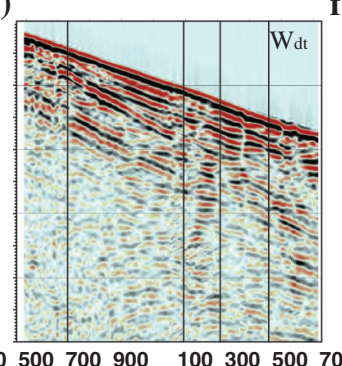

i) c) $100 \quad 300 \quad 500 \quad 700 \quad 900$

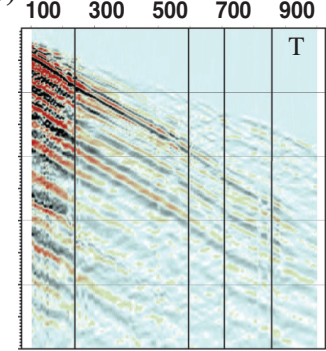

f) g)

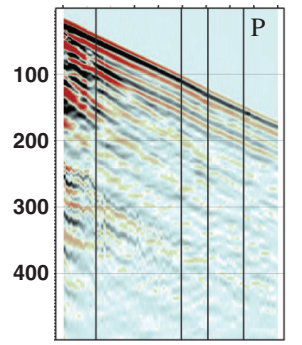

h)

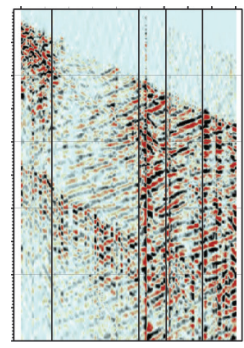

(1)

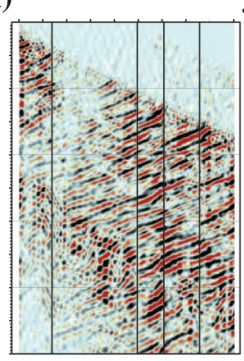

j)
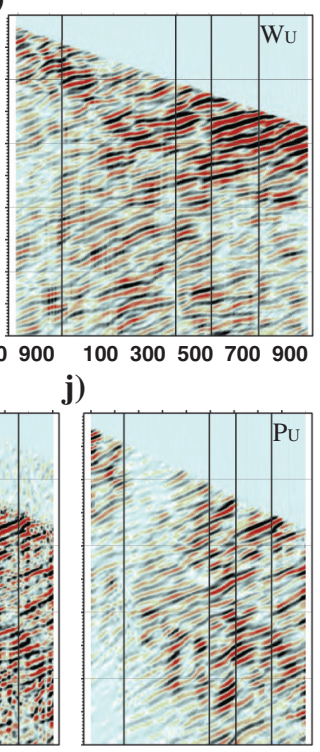

Figure 8. Top: Raw 3C data after component rotation (a) P-primary, (b) R-Radial, and (c) T-Transverse. Middle: Hydrophone data at different stages of processing (d) Raw W data; highlighted by ellipses are (1) Rayleigh tube-wave arrival time mismatches between shots due to water table variations and (2) ambient background tube waves. (e) $W_{\mathrm{dt}^{-}}$after tube-wave removal and (f) $W_{U}$-upgoing wavefield separated. Bottom: Stages of downgoing wavefield removal applied to rotated vertical geophone data $(\mathrm{g})$ and input data $(\mathrm{h})$ after 2D median filter with a spatial window of 13 traces (1) application of 3000 to $6500 \mathrm{~m} / \mathrm{s} f$ - $k$ fan filter with a top mute (j) upgoing signal enhancement with a seven trace median filter followed by a $f-k$ box filter with limits \pm 40 cycles $/ \mathrm{km}$ and 0 to $250 \mathrm{~Hz}$. 
$15 \mathrm{~Hz}$ low cut and 155 to $220 \mathrm{~Hz}$ high cut) prior to stacking. The processing flow is run twice; once for the removal of downgoing tube waves and then again, applied to the upgoing tube waves. Experience shows that wavefield separation of the hydrophone data with all 2D filter algorithms performs better in the FFID domain compared to a common-shot gather. By processing in the FFID domain, inequalities of amplitude and timing between shots are negated.

\section{C GEOPHONE AND HYDROPHONE VSP COMPARISONS}

To qualitatively compare the tube-wave filtered hydrophone data that contains P- and S-pressure fields, with the particle velocity vector fields of the $3 \mathrm{C}$ data, the geophone components were stacked together. The stacked 3C data and hydrophone tube-wave filtered data $\left(W_{\mathrm{dt}}\right)$ are shown in Figure 9a. The $W_{\mathrm{dt}}$ data are of inferior quality and has lower fidelity in comparison to that of the $3 \mathrm{C}$. True amplitudes have not been preserved in the data processing due to AGC functions used during wavefield separation and there are discontinuous sections where tube-wave removal has not been able to recover the entire masked signal. The lack of masked signal recovery happens most commonly at depths where tube waves are reflected and $\mathrm{P}$ - to S-wave conversions occur. The hydrophone data are less continuous than the $3 \mathrm{C}$ data, which in part may be attributed to the lack of a trigger reference geophone and differences in source impulse, which in turn requires very accurate picking of horizons. However, the variation is mostly due to the removal of the tube waves. Despite the lesser quality of $W_{\mathrm{dt}}$, there are obvious similarities with the $\mathrm{P}$ data, some of which have been highlighted in Figure 9a. The $W_{\mathrm{dt}}$ data show clear downgoing $\mathrm{P}$ - and $\mathrm{S}$-wavefields $\left(P_{d}, S_{d}\right)$. Some upgoing energy is present, and variances in $P_{d}$ velocity can be observed in the intervals previously defined by the $\mathrm{P}$ - to $\mathrm{S}$-wave conversions in Figure 8.

The $W_{\mathrm{dt}}$ and $\mathrm{P}$ data were then processed to remove downgoing wavefields. The same data processing flow was used to remove the downgoing wavefields in the $W_{\mathrm{dt}}$ and $P$ profiles, specifically: (1) a 2D median filter with a spatial window of 13 traces, (2) an $f$ - $k$ fan filter removing all downgoing velocities between 3000 to $6500 \mathrm{~m} / \mathrm{s}$, with a top mute killing all noise above the first break picks, and (3) upgoing signal enhancement with a seven-trace median filter followed by an $f$ - $k$ box filter with limits \pm 40 cycles $/ \mathrm{km}$ and 0 to $250 \mathrm{~Hz}$. The results of each step applied to the geophone data has been displayed in Figure $8 \mathrm{~g}-8 \mathrm{j}$.

The resulting hydrophone and geophone $\mathrm{P}$ wave upgoing profiles ( $W_{u}$ and $P_{u}$, respectively) are shown in Figure $9 \mathrm{~b}$ and have very similar features that have been highlighted (by horizontal joiners). The sections in the hydrophone data that were compromised by tube-wave removal have recovered the upgoing $\mathrm{P}$-wave with good (if not surprising) continuity. There is some dissimilarity in amplitudes at later times between the two processed profiles. This is due to the application of AGC during tube-wave removal and lends the $W_{u}$ profile a more continuous appearance than the $P_{u}$ profile. The $P_{u}$ data, however, is of slightly higher frequency content and has fewer undulations. Both methods have resolved reflectors originating at depths of 235, 485, 590, 690, and $900 \mathrm{~m}$ (or 50, 80, 110, 130, and $160 \mathrm{~ms}$ ). The upper-most reflection at $50 \mathrm{~ms}$ is better defined in the $P_{u}$ data and corresponds to the top of the granite $(235 \mathrm{~m})$ and a weak, but clear, reflector can be seen at the base of the massive granite intrusion. Many of the other strong reflections are from structural and alteration features within the granite $(485,590$, and $690 \mathrm{~m})$ and the reflection at $160 \mathrm{~ms}$ is caused by alternating basalt and granite between 890 and $925 \mathrm{~m}$. 
All of these reflectors have been labeled alphabetically with depth from a to $\mathrm{f}$ in Figure 9. To aid correlation of the reflectors to geologic horizons, the acoustic impedance log has been plotted along the depth axis in Figure 9b. Also noticeable in the $W_{u}$ and $P_{u}$ profiles is the occurrence of multiples, particularly in the $P_{u}$ data from the top of the granite and base of the alteration zone. These multiples are indicated by ellipses in Figure $9 \mathrm{~b}$.

Corridor stacks were created from the $W_{u}$ and $P_{u}$ profiles. After conversion to two-way traveltime by adding FB traveltimes, a very tight ( 25 to $50 \mathrm{~ms}$ ) time window from the first breaks was used to mute any multiples from the profiles and generate the upgoing Pwave corridor. These corridors were then stacked to create a single trace that represents only reflected wavefields at the borehole. The hydrophone and vertical component geophone corridor traces were then reproduced three times for visualization and are displayed in Figure 10. In Figure 10, a comparison can be made between the corridor stacks and a trace that has been extracted from the 3D seismic volume along the borehole path. In addition, a synthetic trace generated from borehole $\operatorname{logs}$ is displayed. The synthetic seismic trace was produced by convolving the reflectivity function with a $90^{\circ}$ phase shifted $45 \mathrm{~Hz}$ wavelet. The reflectivity function is determined from density and velocity contrasts, which, in turn, determines the amplitude of the convolved synthetic seismic response. The blockiness of the density model has created anomalous seismic responses at density changes. However, these responses are low in amplitude compared with seismic responses dominated by velocity contrasts in the P-wave FWS data. The low response from density contrasts can be seen in Figure 10 at $550 \mathrm{~m}$ where velocity is relatively constant and density changes. Conversely, a large response due to velocity variations with density constant is displayed between 650 to $700 \mathrm{~m}$.

Visual inspection of the corridor stacks of Figure 10 show that the geophone stack is very similar to that of the hydrophone stack. Both corridor stacks correlate better with the trace extracted from the $3 \mathrm{D}$ volume than the synthetic trace. The poor correlation of the synthetic trace to the extracted trace can be attributed to poor quality FWS data and lack of a wire-line density log. Surprisingly, the hydrophone stack has a better correlation at the base of the massive granite intrusion; however, the geophone has resolved the upper reflectors better. Superficially, there is no clear advantage of the geophone over the hydrophone in the corridor stack. The 3D volume was depth migrated with check shot corrections determined from the hydrophone VSP. A $16 \mathrm{~ms}(80 \mathrm{~m})$ shift was applied to account for refraction static corrections, which used a $5000 \mathrm{~m} / \mathrm{s}$ replacement velocity to correct for the slow velocity regolith layer. The six horizons identified in Figure 9b have correspondingly been labeled a to $\mathrm{f}$ in Figure 10.

As the VSP shotpoint was $28 \mathrm{~m}$ offset from the collar, and BH1 is deviated (dipping $82^{\circ}$ to the south and $15^{\circ}$ offline from the surface seismic crossline), the receivers have an approximate maximum $190 \mathrm{~m}$ lateral aperture from the shotpoint. The lateral aperture of the receivers raises the possibility of seismic imaging from the borehole from such a near collar shotpoint. As such, VSP-common depth point (VSP-CDP) mapping (Dillon and Thomson, 1984) and depth migration were performed on the upgoing wavefield profiles. VSP-CDP mapping converts the profiles to two-way traveltime and places the traces into their true geographic position (assuming a vertically transverse isotropic horizontal layered earth). In Figure 11, the VSP-CDP mapping's of the $W_{u}$ and $P_{u}$ data are

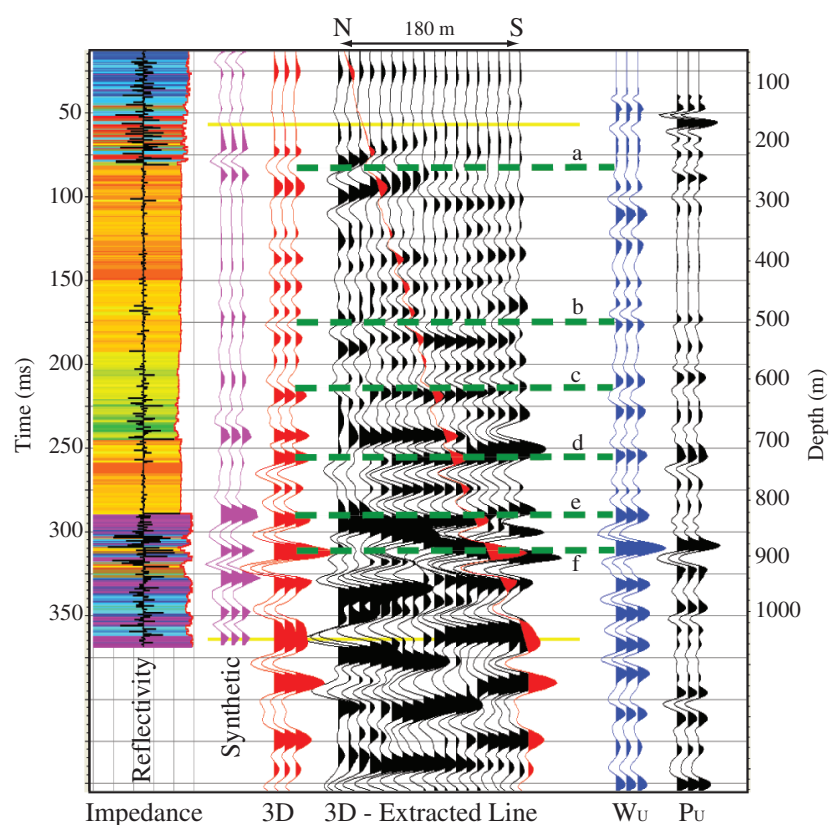

Figure 10. BH1 seismic borehole tie showing the acoustic impedance and reflectivity logs, a synthetic trace derived from convolution of the reflectivity, a $45 \mathrm{~Hz}$ Ricker wavelet with a $90^{\circ}$ phase rotation, a trace and 2D line extracted from the 3D surface seismic along the borehole path, and hydrophone $\left(W_{U}\right)$ and geophone $\left(P_{U}\right)$ corridor stacks.

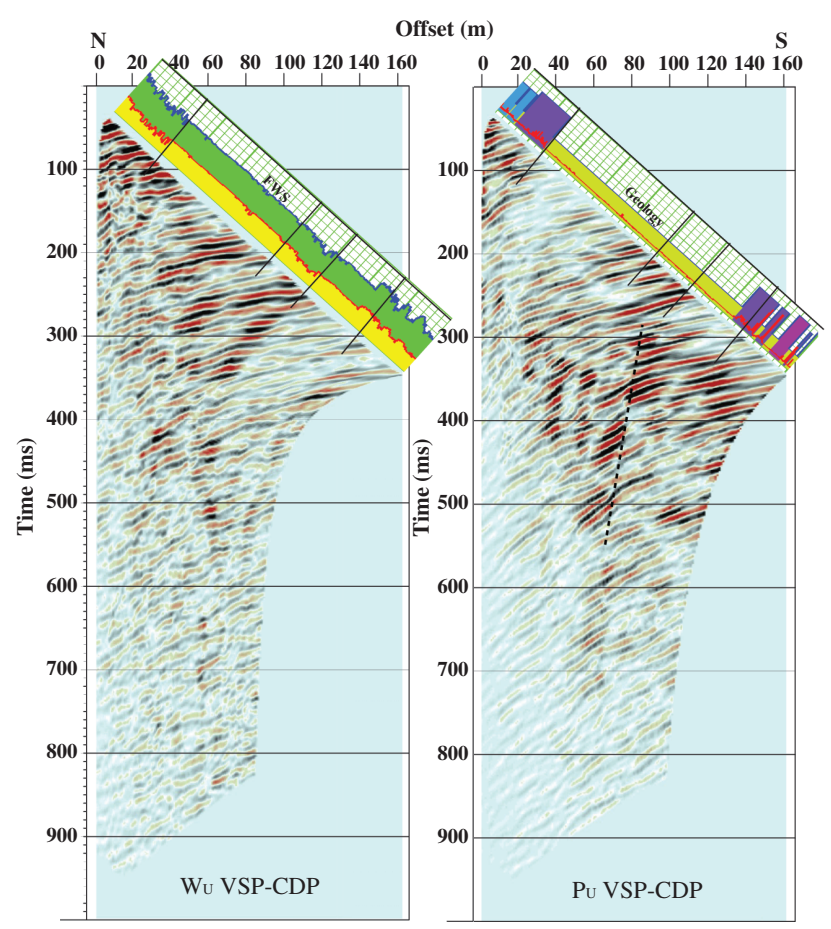

Figure 11. Comparison of upgoing wavefield hydrophone and geophone data after VSP-CDP mapping. The borehole is $28 \mathrm{~m}$ from the shotpoint and dips approximately $82^{\circ}$ to the south. The horizontal (offset) axis is greatly exaggerated. Reflectors in the profiles are clearly dipping to the north. Multiples identified in Figure $9 \mathrm{~b}$ have been transformed onto the CDP image and give the illusion of a fault through the profile as indicated by the dashed line. 
shown. Also shown in Figure 11 are the P- to S-wave conversion markers of Figure 8 and the geology and FWS logs superimposed along the borehole path. The VSP-CDP mapping indicates our reflectors are dipping to the north, in agreement with the documented plunge direction of the Kambalda Anticline. The true seismic dip is not shown because the horizontal axis is exaggerated to see features within the profiles. As previously seen, CDP mapping of the $P_{u}$ data has higher frequency content and a more continuous appearance than its $W_{u}$ counterpart. However, the multiples previously seen in the $P_{u}$ have also been transformed in the mapping process to the detriment of the $P_{u}$ data and give the impression of a fault (Figure 11).

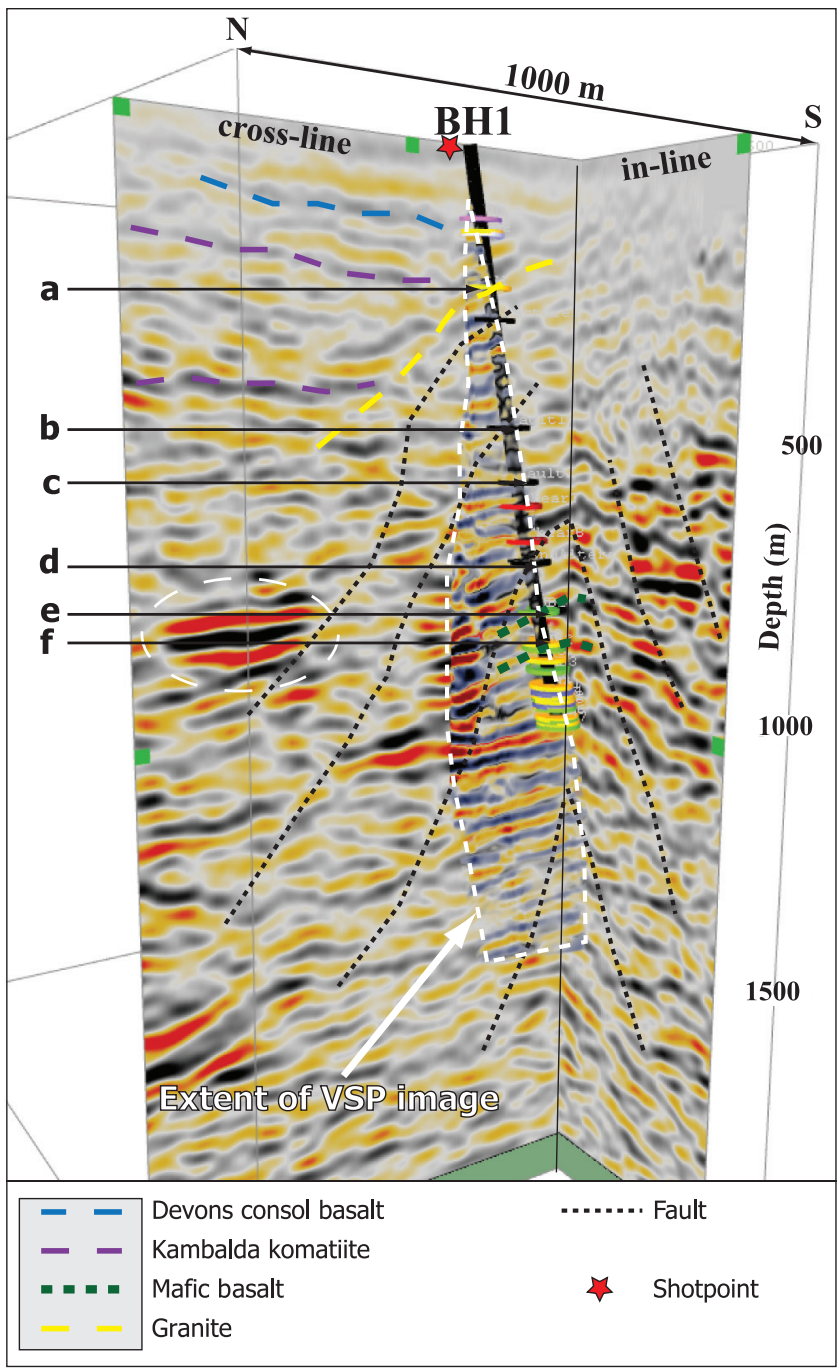

Figure 12. Kirchhoff depth migrated hydrophone VSP image from borehole BH1 inserted (between white dashed lines) into the Kambalda 3D surface seismic cube. The borehole path and VSP is approximately $15^{\circ}$ offline from the crossline. One-dimensional velocity profile derived from the hydrophone VSP was used for time-to-depth conversion of the 3D seismic data and migration of the VSP. Formation tops are shown along the borehole path where yellow-granite, purple-high $\mathrm{MgO}$ basalt, green-mafic basalt, black-inferred fractures/faults, and the two red markers bound the large alteration zone seen in the geology logs.
VSP prestack Kirchhoff depth migration (Dillon, 1988) was conducted on the $W_{u}$ data. A $1 \mathrm{D}$ velocity model ascertained from the hydrophone check shot data was used for the VSP depth migration and time-to-depth conversion of the 3D surface seismic data. The resulting VSP depth migrated has been spliced into the depth converted 3D surface seismic and is shown in Figure 12. Due to the limited lateral shot-receiver aperture, the VSP migration was restricted to a $5^{\circ}$ imaging aperture. This was to ensure correct mapping of horizons. As such, the depth migration has only imaged shallow-dipping structures below the hole. There is a good correlation between the VSP image and 3D seismic with many of the horizons lining up and a strong reflector just below the hole being imaged. In Figure 12, formation tops and reflection events a to $f$ have been marked along the borehole track. A basic interpretation has been made around these markers and faulting in the $3 \mathrm{D}$ seismic cube.

\section{DISCUSSION}

The computed acoustic impedance and reflectivity logs in Figures 6 and 10 strongly suggest that the granite/mafic basalt interface at $830 \mathrm{~m}$ (event e) should create a strong reflector. However, this is not seen in the $W_{u}$ and $P_{u}$ profiles or corridor stacks. It may be that unfavorable survey geometry and/or the configuration of the interface, or, possibly, destructive interference from multiple interfaces, have an effect here. Inspection of the full geology log shows that the section between 828 to $887 \mathrm{~m}$, which is reported as a single mafic basalt unit in the geologic summary, actually includes nine felsic intrusive events. In a similar vein, the strong reflection directly below event e at $903 \mathrm{~m}$ (event $\mathrm{f}$ ) may be due to constructive interference and tuning effects. The convolution of the reflectivity function and model wavelet to form the synthetic trace of Figure 10 does not account for such constructive or destructive interference effects. This would explain why the synthetic corridor stack has a poor correlation with the trace extracted from the $3 \mathrm{D}$ surface seismic $W_{u}$ and $P_{u}$ corridor stacks. Zero-offset forward modeling and AVO analysis of the seismic response may be a better approach for correlation of FWS to seismic data.

There is a strong seismic reflection event to the north of BH1 that has been circled with a white dashed ellipse in Figure 12. This reflection event is of lower frequency and moderately flat lying. This is in contrast to the higher frequency reflection events seen around the borehole where many intrusive events are present. A lower frequency reflection may be caused by interference effects as discussed above. Furthermore, the ultramafic komatiites of Kambalda have a spinifex texture, which is a possible cause of preferential seismic transmission and attenuation. The flat-lying appearance of this reflector is likely due to the reflector paralleling the axis of the Kambalda Anticline. Thus, this reflection could be a potential western flank UM/Lunnon Basalt target.

Structural analysis of the 3D cube away from the borehole surmises very steep WNW dipping reverse faults. The proximity of these faults to the borehole, the amount of granite intersected in the borehole, and the large alteration zone within the granite intrusion strongly suggests that the borehole has intersected an extension of the Loretto Thrust or similar structure.

It has now become apparent that further VSP surveys are needed to depth calibrate the 3D seismic cube in areas not effected by large scale faulting, shears, and intrusions, and to help resolve geologic complexity of the area covered by the $3 \mathrm{D}$ surface survey. This will 
enable an improved exploration strategy and subsequent verification through drilling.

\section{CONCLUSIONS}

The results of these field experiments and the data processing methodology used demonstrate the potential of hydrophone VSP surveys in the small-diameter boreholes typical of hard rock exploration. It has been shown that borehole hydrophones are capable of imaging structure in a complex environment, despite significant tube-wave contamination. This is not easily achieved, and care at the acquisition and processing stages must be taken.

Nonstandard wavefield separation successfully removed strong coherent tube-wave noise. The additional wavefield separation steps required to remove high-amplitude tube waves does degrade the overall result with some fidelity and coherency being lost in the final upgoing wavefield profiles and VSP-CDP stacks. However, a comparison of hydrophone and geophone VSP surveys show similar reflections in the wavefield separated data. When many thin beds are present, hydrophone and geophone VSP corridor stacks have a better correlation with surface seismic data than FWS derived synthetic data.

Success of tube-wave wavefield separation methods from hydrophone data depends critically upon having well-sampled data, preconditioning of field data, and processing in the field record (FFID) domain. To collect unaliased tube-wave data in a hard rock environment, the data should be collected at a maximum of $5 \mathrm{~m}$ intervals to avoid aliasing frequencies below $150 \mathrm{~Hz}$; more preferably, data should be collected at $3 \mathrm{~m}$ station spacing (to collect unaliased frequencies up to $200 \mathrm{~Hz}$ or less. If hydrophone strings are designed around such parameters, using multiple small moves with larger spaced elements could be avoided, thus avoiding potential aliasing in the wavenumber domain and reducing the potential of trace-totrace amplitude and noise imbalances. Careful editing of bad and noisy traces and preconditioning of data to increase $\mathrm{S} / \mathrm{N}$ and equalize trace-to-trace amplitudes prior to any $2 \mathrm{D}$ filtering is vital. In addition to this, processing in the FFID domain reduces the potential of processing artifacts caused by shot-to-shot and receiver repositioning disparities.

Improvements in field data acquisition through the use of highviscosity drilling fluids and baffle systems are also recommended. The increased coupling of hydrophones and suppression of tubewave energy through these technologies will greatly enhance the performance of hydrophone VSP imaging.

The hydrophone data were collected in a fraction of the time compared to clamping geophone equipment of comparable value with significantly less risk of equipment loss. Despite the compromises in raw data quality of hydrophone data compared to clamped geophones, the usable results after processing are similar; thus, demonstrating the cost effectiveness of using hydrophones in difficult hard rock environments.

\section{ACKNOWLEDGMENTS}

This work has been supported by the Deep Exploration Technologies Cooperative Research Centre, whose activities are funded by the Australian Government's Cooperative Research Centre Programme. We are grateful to ASTO Geophysical Consulting Pty Ltd for donating borehole geophone equipment for the $3 \mathrm{C}$ trial, $\mathrm{BHP}$ Billiton for donating borehole time and borehole information costs, and a special thanks goes to Anousha Hashemi and John Emerson for facilitating the surveys. We also thank GEDCO for VISTA software under their university program.

\section{REFERENCES}

Adam, E., B. Milkereit, B. Roberts, and D. Schmitt, 2000, VSP survey at a VMS deposit, Matagami, Quebec: 70th Annual International Meeting, SEG, Expanded Abstracts, 1126-1129.

Bellefleur, G., L. Matthews, B. Roberts, B. McMonnies, M. Salisbury, G. Perron, D. Snyder, and J. McGaughey, 2004, Downhole seismic imaging of the Victor Kimberlite, James Bay Lowlands, Canada: A feasibility study: 74th Annual International Meeting, SEG, Expanded Abstracts, 1229-1232.

Beresford, S., R. Cas, Y. Lahaye, and M. Jane, 2002, Facies architecture of an Archean komatiite-hosted Ni-sulphide ore deposit, Victor, Kambalda, Western Australia: Implications for komatiite lava emplacement: Journal of Volcanology and Geothermal Research, 118, 57-75, doi: 10.1016/ S0377-0273(02)00250-0.

Blias, E., 2007, VSP wavefield separation: Wave-by-wave optimization approach: Geophysics, 72, no. 4, T47-T55, doi: 10.1190/1.2744124.

Calvert, A. J., and Y. Li, 1999, Seismic reflection imaging over a massive sulfide deposit at the Matagami mining camp, Quebec: Geophysics, 64, 24-32, doi: 10.1190/1.444521.

Cheng, C. H., and M. N. Töksoz, 1982, Generation, propagation and analysis of tube waves in a borehole: SPWLA 23 Annual Logging Symposium, SPWLA.

Cosma, C., 2003, Multi-azimuth VSP for rock characterization of deep nuclear waste disposal sites in Finland, in D. W. Eaton, B. Milkereit, and M. H. Salisbury, eds., Hardrock seismic exploration: SEG.

Cosma, C., and P. Heikkinen, 1996, Seismic investigations for the final disposal of spent nuclear fuel in Finland: Journal of Applied Geophysics, 35, no. 2-3, 151-157, doi: 10.1016/0926-9851(96)00016-X.

Dillon, P. B., 1988, Vertical seismic profile migration using the Kirchhoff integral: Geophysics, 53, 786-799, doi: 10.1190/1.4442514.

Dillon, P. B., and R. C. Thomson, 1984, Offset source VSP surveys and their image reconstruction: Geophysical Prospecting, 32, 790-811, doi: 10 .1111/gpr.1984.32.issue-5.

Eaton, D., S. Guest, B. Milkereit, W. Bleeker, D. Crick, D. Schmitt, and M. H. Salisbury, 1996, Seismic imaging of massive sulfide deposits; Part III, Borehole seismic imaging of near-vertical structures: Economic Geology, 91, no. 5, 835-840, doi: 10.2113/gsecongeo.91.5.835.

Greenhalgh, S. A., and S. Bierbaum, 2000, Underground seismic reflection experiment in a gold mine: Exploration Geophysics, 31, 321-327, doi: 10 .1071/EG00321.

Greenhalgh, S. A., I. M. Mason, and C. Sinadinovski, 2000, In-mine seismic delineation of mineralization and rock structure: Geophysics, 65, 1908 1919, doi: 10.1190/1.1444875.

Greenwood, A., J. C. Dupuis, H. Abdulal, and A. Kepic, 2012, Rigid corrugated baffle system for tube-wave suppression in deep boreholes: 82nd Annual International Meeting, SEG, Expanded Abstracts, doi: 10 $.1190 /$ segam2012-0972.1.

Greenwood, A., J. C. Dupuis, A. Kepic, and M. Urosevic, 2011, Borehole hydrophone acquisition - Some pitfalls and solutions: Borehole Geophysics Workshop, Emphasis on 3D VSP, EAGE.

Gresham, J. J., 1986, Depositional environments of volcanic-peridotite-associated nickel sulfide deposits with special reference to the Kambalda dome: Geology and metallogeny of copper deposits: Springer Verlag, 63-90.

Gulati, J., 1998, Borehole seismic surveying: 3C-3D VSP and land vertical cable analysis: Master's thesis, University of Calgary.

Gulati, J. S., R. R. Stewart, and B. H. Hoffe, 2001, Vertical hydrophone cable acquisition and imaging on land: Geophysics, 66, 1190-1194, doi: $10.1190 / 1.1487065$.

Hardage, B. A., 2000, Vertical seismic profiling: Principles: Pergamon.

Huang, C. F., and J. A. Hunter, 1984, The tube-wave method of estimating in-situ rock fracture permeability in fluid-filled boreholes: Geoexploration, 22, no. 3-4, 245-259, doi: 10.1016/0016-7142(84) 90015-2.

Juhlin, C., 1990, Interpretation of the reflections in the Siljan Ring area based on results from the Gravberg-1 borehole: Tectonophysics, 173, 345-360, doi: 10.1016/0040-1951(90)90229-2.

Juhlin, C., J. Lindgren, and B. Collini, 1991, Interpretation of seismic reflection and borehole data from Precambrian rocks in the Dala sandstone area, central Sweden: First Break, 9, 24-36, doi: 10.3997/1365-2397 .1991002 .

Marzetta, T. L., M. Orton, A. Krampe, L. K. Johnston, and P. C. Wuenschel, 1988, A hydrophone vertical seismic profiling experiment: Geophysics, 53, 1437-1444, doi: 10.1190/1.442423.

Miao, X.-G., W. M. Moon, and B. Milkereit, 1995, A multi-offset, three-component VSP study in the Sudbury Basin: Geophysics, 60, 341-353, doi: 10.1190/1.1443770. 
Milligan, P. A., J. W. Rector I, and R. W. Bainer, 1997, Hydrophone VSP imaging at a shallow site: Geophysics, 62, 842-852, doi: $10.1190 / 1$ .1444193 .

Perron, G., D. W. Eaton, B. Elliot, and D. Schmitt, 2003, Application of downhole seismic imaging to map near-vertical structures: Normetal (Abitibi Greenstone Belt), Quebec, in D. W. Eaton, B. Milkereit, and M. H. Salisbury, eds., Hardrock seismic exploration: SEG.

Sheriff, R. E., 2002, Encyclopedic dictionary of applied geophysics: SEG. Stone, W. E., and N. J. Archibald, 2004, Structural controls on nickel sulphide ore shoots in Archaean komatiite, Kambalda, WA: The volcanic trough controversy revisited: Journal of Structural Geology, 26, no. 6-7, 1173-1194, doi: 10.1016/j.jsg.2003.11.014.

Stone, W. E., S. W. Beresford, and N. J. Archibald, 2005, Structural setting and shape analysis of nickel sulfide shoots at the Kambalda Dome, Western Australia: Implications for deformation and remobilization:
Economic Geology, 100, no. 7, 1441-1455, doi: 10.2113/gsecongeo .100 .7 .1441 .

Stone, W. E., and E. E. Masterman, 1998, Kambalda nickel deposits in D. A Berkman, and D. H. Mackenzie, eds., Geology of Australian and Papua New Guinean mineral deposits, Australasian Institute of Mining and Metallurgy, 347-356.

Urosevic, M. A. Kepic, E. Stolz, and C. Juhlin, 2007, Seismic exploration of ore deposits in Western Australia: 5th Decennial International Conference on Mineral Exploration, 525-534.

Urosevic, M., E. Stolz, and S. Massey, 2005, Seismic exploration for gold in a hard rock environment - Yilgarn Craton, Western Australia: 67th Annual International Conference and Exhibition, EAGE, Extended Abstracts, G009.

White, J. E., 1983, Underground sound, application of seismic waves: Elsiever Science. 